BMJ Open

Diabetes

Research

\& Care

\title{
Serum creatinine levels and risk of incident type 2 diabetes mellitus or dysglycemia in middle-aged Japanese men: a retrospective cohort study
}

\author{
Mamoru Takeuchi, ${ }^{1}$ Hironori Imano, ${ }^{1}$ Isao Muraki, ${ }^{1}$ Yuji Shimizu, ${ }^{2}$ \\ Mina Hayama-Terada, ${ }^{2}$ Akihiko Kitamura, ${ }^{3}$ Takeo Okada, ${ }^{2}$ Masahiko Kiyama, ${ }^{2}$ \\ Hiroyasu Iso ${ }^{1}$
}

\begin{abstract}
To cite: Takeuchi M, Imano H, Muraki I, et al. Serum creatinine levels and risk of incident type 2 diabetes mellitus or dysglycemia in middle-aged Japanese men: a retrospective cohort study. BMJ Open Diab Res Care 2018;6:e000492. doi:10.1136/ bmjdrc-2017-000492
\end{abstract}

Received 20 November 2017 Revised 8 January 2018 Accepted 5 February 2018

Check for updates

${ }^{1}$ Department of Social Medicine, Public Health, Graduate School of Medicine, Osaka University, Osaka, Japan ${ }^{2}$ Osaka Center for Cancer and Cardiovascular Disease Prevention, Osaka, Japan ${ }^{3}$ Research Team for Social Participation and Community Health, Tokyo Metropolitan Institute of Gerontology, Tokyo, Japan

Correspondence to Dr Hiroyasu Iso;

iso@pbhel.med.osaka-u.ac.jp

\section{ABSTRACT}

Objective To assess the association between low serum creatinine levels and an increased risk of type 2 diabetes mellitus and dysglycemia.

Research design and methods We conducted a retrospective cohort study of 3313 Japanese male workers aged 30-55 years, who underwent annual health checkups during 2001-2008 and showed no type 2 diabetes mellitus, and underwent follow-up examinations until March 2013. Dysglycemia was defined as a fasting plasma glucose concentration of $\geq 110 \mathrm{mg} / \mathrm{dL}(6.1 \mathrm{mmol} / \mathrm{L})$, or a non-fasting plasma glucose concentration of $\geq 140 \mathrm{mg} /$ $\mathrm{dL}(7.8 \mathrm{mmol} / \mathrm{L})$. A Cox proportional model was used to calculate HRs and $95 \%$ Cls for developing type 2 diabetes mellitus or dysglycemia.

Results During the median 6.7-year follow-up, there were 207 cases of incident type 2 diabetes mellitus and 596 cases of incident dysglycemia, including 115 cases of type 2 diabetes mellitus among the subjects with normal glucose concentrations at baseline. After adjustment for age, body mass index and known diabetes risk factors, the multivariable HR of type 2 diabetes mellitus for the lowest category of serum creatinine $(<0.7 \mathrm{mg} / \mathrm{dL})$ vs the highest category $(0.9-1.1 \mathrm{mg} / \mathrm{dL})$ was $1.9(95 \% \mathrm{Cl} 1.2$ to $2.9 ; \mathrm{P}$ for trend 0.03). The multivariable HRs of dysglycemia for the lowest category of serum creatinine versus the highest category was 1.5 (95\% Cl 1.1 to 1.9 ; P for trend 0.01$)$.

Conclusions Low serum creatinine levels were associated with an increased risk of type 2 diabetes mellitus and dysglycemia.

\section{INTRODUCTION}

Type 2 diabetes mellitus is one of the leading causes of preventable death in the world, with stroke, myocardial infarction and other cardiovascular diseases being the most common causes of death for adults with diabetes. ${ }^{1}$ Type 2 diabetes mellitus is an independent major risk factor for these causes of death, and risk factors for type 2 diabetes mellitus and cardiovascular disease overlap. ${ }^{1}$ Prediabetes is associated with an increased risk of both type 2 diabetes mellitus and cardiovascular disease. ${ }^{23}$

\section{Significance of the study}

What is already known about this subject?

- Skeletal muscle mass and the concentration of serum creatinine (a byproduct of muscle metabolism) are associated with type 2 diabetes mellitus, but whether serum creatinine is associated with risk of incident dysglycemia remains unclear.

\section{What are the new findings?}

- Low serum creatinine concentrations were positively associated with both incident dysglycemia and incident type 2 diabetes mellitus over a 6.7-year follow-up period, independent of other major risk factors for type 2 diabetes mellitus including age, body mass index, alcohol intake, physical activity and family history of diabetes.

How might these results change the focus of research or clinical practice?

- Low serum creatinine concentrations may be indicative of a risk of incident dysglycemia, providing an early opportunity for prevention of type 2 diabetes mellitus and cardiovascular disease through lifestyle modifications.

A meta-analysis of 15 cohort studies showed that elevated postprandial glucose values and non-diabetic impaired glucose tolerance were associated with an approximately threefold increased risk of developing coronary heart disease or cardiovascular events. ${ }^{4}$ Thus, type 2 diabetes mellitus and dysglycemia are important targets to be focused on for global health.

Skeletal muscle is the predominant site of insulin-mediated plasma glucose uptake in the postprandial state ${ }^{5}$; thus, low skeletal muscle mass is associated with hyperglycemia after an oral glucose load and with insulin resistance and diabetes. ${ }^{7}$ Serum creatinine is the only substance metabolized by skeletal 
muscle and is closely associated with total skeletal muscle mass. ${ }^{8}$ Therefore, it is suggested that low serum creatinine is a risk factor for type 2 diabetes mellitus and dysglycemia.

A limited number of previous studies have shown an association of low serum creatinine with type 2 diabetes mellitus. For instance, a case-control study of 1122 subjects in Trinidad and Tobago showed an association of low serum creatinine with type 2 diabetes mellitus. ${ }^{9}$ Likewise, a cross-sectional study of 1017 patients with morbid obesity aged 18-75 years showed a positive association between serum creatinine and diabetes prevalence. ${ }^{10}$ These studies, however, were case-control or cross-sectional studies, and therefore their level of evidence was not high. Two previous Japanese cohort studies showed that lower serum creatinine was associated with an approximately 1.5-fold to 2-fold increased risk of type 2 diabetes mellitus. ${ }^{11}{ }^{12}$ However, no cohort studies have examined the association of low serum creatinine with risk of dysglycemia, defined as shown below in the section "Research design and methods".

Therefore, we aimed to investigate whether low serum creatinine, a surrogate marker of skeletal muscle mass, was associated with an increased risk of incident dysglycemia including type 2 diabetes mellitus.

\section{RESEARCH DESIGN AND METHODS Study cohort}

The study subjects were 3900 men aged $30-55$ years at entry who worked for any of 50 companies in Osaka, the third largest metropolitan city in Japan. Sixty-seven per cent of subjects were white-collar workers and most retired at 60 years of age. All subjects had undergone annual health check-ups at the Osaka Center for Cancer and Cardiovascular Disease Prevention, with baseline surveys conducted between 2001 and 2008, and follow-ups for the incidence of diabetes and dysglycemia conducted until March 2013. Of the 3900 subjects, we excluded 384 because of loss of follow-up, 135 with diabetes as defined below, and 68 with abnormally high levels of serum creatinine $(>1.1 \mathrm{mg} / \mathrm{dL})$. The remaining 3313 subjects were used for the present analysis. The mean number of check-up visits was 7.0, and the median follow-up period was 6.7 years. The average proportion of the subjects who underwent annual health check-ups each year was $91.6 \%$. Serum creatinine levels were grouped into the following four categories: $<0.70,0.70-0.79,0.80-0.89$ and $0.9-1.1 \mathrm{mg} / \mathrm{dL}$.

\section{Baseline examinations and follow-up study}

An interview was conducted to ascertain the following: number of cigarettes smoked per day; typical weekly intake of ethanol measured in units of 'go' (a Japanese traditional unit of volume; one 'go' is $180 \mathrm{~mL}$ and contains $23 \mathrm{~g}$ of ethanol), which was then converted to grams of ethanol per day; family history of diabetes; leisure-time physical activities (one or more regular exercise sessions per week or none) and medication use for diabetes mellitus, hypertension or hyperlipidemia. Family history of diabetes was defined as the presence of at least one first-degree relative (father or mother) with diabetes. Blood pressures were measured on the right arm, in a sitting position after at least 5 min rest, by trained physicians using a standard mercury sphygmomanometer. Height was measured with the participants' shoes removed and weight was measured with the participants wearing light clothing. Body mass index (BMI) was calculated as weight $(\mathrm{kg})$ divided by the square of height $\left(\mathrm{m}^{2}\right)$. Blood was drawn from seated participants into a plain, siliconized glass tube and the serum was separated. Fasting was not required. Serum glucose was measured by the hexokinase method and serum creatinine was measured by the enzymatic method. The normal range of serum creatinine measured by the enzymatic method was $0.6-1.1 \mathrm{mg} / \mathrm{dL}$. All measurements of serum glucose and serum creatinine concentrations were performed at the laboratory of the Osaka Center for Cancer and Cardiovascular Disease Prevention. Diabetes was defined according to the report of a WHO/International Diabetes Federation consultation ${ }^{13}$ as a fasting plasma glucose concentration (FPG) of $\geq 126 \mathrm{mg} / \mathrm{dL}$ $(7.0 \mathrm{mmol} / \mathrm{L})$, and $/$ or a non-fasting plasma glucose concentration (NFG) of $\geq 200 \mathrm{mg} / \mathrm{dL}(11.1 \mathrm{mmol} / \mathrm{L})$, and/or use of medication for diabetes. Dysglycemia was defined as a FPG of $\geq 110 \mathrm{mg} / \mathrm{dL}(6.1 \mathrm{~mol} / \mathrm{L})$, and $/$ or a $\mathrm{NFG}$ of $\geq 140 \mathrm{mg} / \mathrm{dL}(7.8 \mathrm{mmol} / \mathrm{L})$, so that dysglycemia included diabetes and intermediate hyperglycemia.

\section{Statistical analysis}

We tested differences in the baseline characteristics according to serum creatinine categories using analysis of variance for continuous variables and $\mathrm{X}^{2}$ test for categorical variables. Person-years were calculated as the sum of individual follow-up time until the occurrence of incident type 2 diabetes mellitus or dysglycemia, the final visit for health check-up or the end of follow-up. Cox proportional hazards regression models were used to estimate HRs and $95 \%$ CIs for the new onset of type 2 diabetes mellitus and dysglycemia with the highest category of serum creatinine as a reference. A test for trend between serum creatinine categories and risk of type 2 diabetes mellitus or dysglycemia was also conducted. Covariates included age (years), BMI $\left(\mathrm{kg} / \mathrm{m}^{2}\right)$, smoking status (never, former or current smokers; $<20$ or $\geq 20$ cigarettes/day), alcohol intake (never, former or current: $<23,23-45$ or $\geq 46 \mathrm{~g} /$ day of ethanol), family history of diabetes (yes or no) and leisure-time physical activity (yes or no). Covariate data were missing for three male participants, who were excluded from the analysis.

All statistical analyses were performed using the SAS System (V.9.4; SAS Institute, Cary, North Carolina, USA). All statistical tests were two-sided, and $\mathrm{P}$ values $<0.05$ were regarded as statistically significant. 
Table 1 Baseline characteristics of participants according to serum creatinine categories

\begin{tabular}{|c|c|c|c|c|c|c|}
\hline & \multicolumn{5}{|c|}{ Serum creatinine $(\mathrm{mg} / \mathrm{dL})$} & \multirow{2}{*}{$\begin{array}{l}\text { P value for } \\
\text { difference }\end{array}$} \\
\hline & $0.38-0.69$ & $0.70-0.79$ & $0.80-0.89$ & $0.90-1.10$ & Total & \\
\hline Age, years & $42.4(7.6)$ & $42.3(7.1)$ & $42.2(7.2)$ & $43.2(7.2)$ & $42.5(7.2)$ & 0.02 \\
\hline Glucose, mmol/L & $5.58(0.69)$ & $5.50(0.66)$ & $5.48(0.56)$ & $5.52(0.61)$ & $5.51(0.62)$ & 0.04 \\
\hline Fasting & 58.5 & 64.2 & 69.4 & 69.2 & 66.6 & $<0.01$ \\
\hline Body mass index, $\mathrm{kg} / \mathrm{m}^{2}$ & $23.2(3.3)$ & $23.5(3.2)$ & $23.7(2.9)$ & $24.3(3.2)$ & $23.7(3.1)$ & $<0.01$ \\
\hline Family history & 21.2 & 13.7 & 13.9 & 14.8 & 14.9 & 0.08 \\
\hline High physical activity & 35.7 & 35.2 & 38.8 & 45.0 & 38.8 & $<0.01$ \\
\hline \multicolumn{7}{|l|}{ Smoking status } \\
\hline Never smokers & 19.8 & 23.4 & 27.4 & 30.4 & 26.1 & $<0.01$ \\
\hline Past smokers & 16.1 & 20.1 & 25.6 & 27.1 & 23.2 & $<0.01$ \\
\hline \multicolumn{7}{|l|}{ Current smokers } \\
\hline$<20$ cigarettes/day & 11.6 & 9.6 & 8.8 & 9.5 & 9.5 & 0.33 \\
\hline$\geq 20$ cigarettes/day & 52.5 & 46.8 & 38.2 & 33.0 & 41.2 & $<0.001$ \\
\hline Non-drinkers, & 20.3 & 21.6 & 21.9 & 26.2 & 22.7 & 0.01 \\
\hline \multicolumn{7}{|l|}{ Light drinkers } \\
\hline$<23 \mathrm{~g}$ ethanol/day & 41.0 & 47.5 & 50.8 & 48.7 & 48.2 & 0.02 \\
\hline \multicolumn{7}{|l|}{ Moderate drinkers } \\
\hline 23-45 g ethanol/day & 20.9 & 19.7 & 17.4 & 15.1 & 17.9 & $<0.01$ \\
\hline \multicolumn{7}{|l|}{ Heavy drinkers } \\
\hline$\geq 46 \mathrm{~g}$ ethanol/day & 17.8 & 11.3 & 9.9 & 9.8 & 11.1 & $<0.01$ \\
\hline
\end{tabular}

Data are presented as mean (SD) or \%.

\section{RESULTS}

Table 1 lists mean values and prevalence of baseline characteristics according to the four categories of serum creatinine levels.

Serum creatinine levels were positively associated with age and BMI, and inversely associated with plasma glucose concentration and the prevalence of high physical activity. No association was found between the serum creatinine level and fasting glucose and non-fasting glucose levels. The correlation coefficients between the serum creatinine level and fasting and non-fasting glucose levels were 0.02 and -0.04 , respectively. During the median 6.7-year follow-up of the 3313 participants totaling 21856 person-years, we identified 207 cases of incident type 2 diabetes mellitus. The multivariable HR of incident type 2 diabetes mellitus for the lowest (0.38$0.69 \mathrm{mg} / \mathrm{dL})$ versus the highest $(0.9-1.1 \mathrm{mg} / \mathrm{dL})$ serum creatinine category was 1.9 (95\% CI 1.2 to 2.9 ; P for trend 0.03) (table 2).

In the stratification analysis at median age (43 years) and BMI $\left(25 \mathrm{~kg} / \mathrm{m}^{2}\right)$, the excess risk remained statistically significant for the older subjects and subjects with obesity. In the stratification analysis with or without high physical activity, an interaction between physical activity and the baseline creatinine level for type 2 diabetes mellitus was observed. Furthermore, an interaction between a family history of type 2 diabetes mellitus and the baseline creatinine level for type 2 diabetes mellitus was observed.
We analyzed the risk of incident dysglycemia, including type 2 diabetes mellitus, from 3046 participants with normal glucose levels at baseline. During the median 6.7-year follow-up totaling 20302 person-years, we identified 596 cases of incident dysglycemia, including 115 cases of incident type 2 diabetes mellitus. The multivariable HR of incident dysglycemia for the lowest versus the highest serum creatinine category was 1.5 (95\% CI 1.1 to 1.9; P for trend 0.01) (table 3).

In the stratification analysis at median age (43 years) and BMI $\left(25 \mathrm{~kg} / \mathrm{m}^{2}\right)$, the excess risk remained statistically significant for the younger subjects and subjects with no obesity. The multivariable HR of incident type 2 diabetes mellitus among subjects with normal glucose levels at baseline for the lowest versus the highest serum creatinine category was 1.9 (95\% CI 1.0 to 3.4; P for trend 0.10 ). The magnitude of the excess risk of incident type 2 diabetes mellitus among subjects with normal glucose levels was the same as that among subjects without type 2 diabetes mellitus (table 3 ).

\section{DISCUSSION}

In this 6.7-year prospective cohort study of 3313 Japanese middle-aged men, we found that low serum creatinine levels were positively associated with an increased risk of incident type 2 diabetes mellitus, independent of other major risk factors for type 2 diabetes mellitus such 
Table 2 HR and 95\% Cls of incident diabetes according to serum creatinine categories among subjects without diabetes at baseline

\begin{tabular}{|c|c|c|c|c|c|c|c|}
\hline & & \multicolumn{6}{|c|}{ Serum creatinine $(\mathrm{mg} / \mathrm{dL})$} \\
\hline & & $0.38-0.69$ & $0.70-0.79$ & $0.80-0.89$ & $0.90-1.10$ & Total & P for trend \\
\hline Total subjects at risk & & 356 & 1028 & 1155 & 776 & 3313 & \\
\hline Age-adjusted HR $(95 \% \mathrm{Cl})$ & & $1.7(1.1 \text { to } 2.6)^{\star \star}$ & $0.9(0.6$ to 1.3$)$ & 0.9 (0.6 to 1.3$)$ & 1.00 & & $<0.001$ \\
\hline Multivariable HR (95\% Cl) & & $1.9(1.2 \text { to } 2.9)^{\star \star}$ & $1.0(0.7$ to 1.5$)$ & $1.0(0.7$ to 1.5$)$ & 1.00 & & 0.03 \\
\hline Age $\geq 43$ years & Cases/subjects & $23 / 166$ & $36 / 478$ & $41 / 540$ & $40 / 407$ & $140 / 1591$ & \\
\hline Multivariable† HR $(95 \% \mathrm{Cl})$ & & $1.9(1.1 \text { to } 3.3)^{\star}$ & $0.9(0.6$ to 1.5$)$ & 0.9 (0.6 to 1.4$)$ & 1.00 & & 0.08 \\
\hline $\mathrm{BMI}<25 \mathrm{~kg} / \mathrm{m}^{2}$ & Cases/Subjects & $19 / 253$ & $22 / 725$ & $33 / 787$ & $23 / 486$ & $97 / 2251$ & \\
\hline Multivariable† HR $(95 \% \mathrm{Cl})$ & & 1.7 (0.9 to 3.1$)$ & 0.7 (0.4 to 1.3$)$ & $1.0(0.6$ to 1.7$)$ & 1.00 & & 0.38 \\
\hline Multivariableł HR $(95 \% \mathrm{Cl})$ & & $1.2(0.5$ to 3.3$)$ & $1.3(0.5$ to 3.0$)$ & 0.9 (0.4 to 2.2$)$ & 1.00 & & 0.6 \\
\hline $\begin{array}{l}\text { Without family history of } \\
\text { diabetes }\end{array}$ & Cases/subjects & $27 / 279$ & $43 / 887$ & $52 / 661$ & $43 / 661$ & $165 / 2821$ & \\
\hline Multivariableł HR $(95 \% \mathrm{Cl})$ & & $2.3(1.4 \text { to } 3.7)^{\star \star}$ & $0.9(0.6$ to 1.5$)$ & $1.1(0.7$ to 1.7$)$ & 1.00 & & 0.01 \\
\hline With high physical activity & Cases/subjects & $7 / 126$ & $21 / 361$ & $20 / 448$ & $20 / 349$ & $68 / 1284$ & \\
\hline Multivariable§ HR (95\% Cl) & & $1.2(0.7$ to 2.3$)$ & $1.2(0.6$ to 2.2$)$ & $1.0(0.5$ to 1.8$)$ & 1.00 & & 0.6 \\
\hline Without high physical activity & Cases/subjects & $28 / 228$ & $36 / 667$ & $43 / 707$ & $32 / 427$ & $139 / 2029$ & \\
\hline Multivariable§ HR (95\% Cl) & & $2.3(1.4 \text { to } 4.0)^{\star \star}$ & $1.0(0.6$ to 1.6$)$ & $1.1(0.7$ to 1.8$)$ & 1.00 & & 0.02 \\
\hline
\end{tabular}

Test for significance: ${ }^{*} \mathrm{P}<0.05,{ }^{* *} \mathrm{P}<0.01$.

†Adjusted for age, BMI, family history, smoking status, alcohol intake category and leisure time physical activity.

¥Adjusted for age, BMI, smoking status, alcohol intake category and leisure time physical activity.

$\S$ Adjusted for age, BMI, family history, smoking status and alcohol intake category. Median age: 43 years.

BMI, body mass index.

as age, BMI, alcohol intake, leisure-time physical activity and family history of diabetes. These associations did not differ substantially between older and younger participants, but were more marked for overweight subjects. Furthermore, we demonstrated that low serum creatinine levels were also positively associated with an increased risk of incident dysglycemia. The present study is the first to our knowledge to report that low serum creatinine is a predictor for both incident type 2 diabetes mellitus and dysglycemia. The magnitude of excess risk of type 2 diabetes mellitus associated with low serum creatinine levels was similar to that reported in a previous 4-year cohort study of 8570 Japanese middle-aged men, which showed that the multivariable OR of diabetes for serum creatinine levels of $0.40-0.60 \mathrm{mg} / \mathrm{dL}$ was $1.91(95 \%$ CI 1.44 to 2.54 ) compared with levels of $0.71-0.80 \mathrm{mg} / \mathrm{dL} .^{11}$ A similar result was reported in a 5.6-year cohort study of Japanese men and women, that is, that the multivariable HR of diabetes incidence in men for serum creatinine levels of $<0.7 \mathrm{mg} / \mathrm{dL}$ was 1.40 (95\% CI 1.05 to 1.87 ) compared with levels of $0.9-1.2 \mathrm{mg} / \mathrm{dL}^{12}$ A 4.5 -year follow-up of 2676 Korean men and women aged 18-75 years indicated that decreased serum creatinine, defined as a difference between follow-up and baseline creatinine, was an independent risk factor of diabetes, with a multivariable OR of 1.89 (95\% CI 1.13 to 3.15$).{ }^{14}$

Serum creatinine levels are correlated with skeletal muscle mass or lean mass, ${ }^{15} 16$ and lower serum creatinine levels reflect reduced skeletal muscle mass. Skeletal muscle is the major site of glucose uptake in the postprandial state in humans; under euglycemic hyperinsulinemic conditions, about $80 \%-90 \%$ of glucose uptake occurs in skeletal muscle. ${ }^{17}$ Reduced glucose uptake in skeletal muscle is considered to be a primary pathogenesis for insulin resistance and type 2 diabetes mellitus, that is evident decades before overt hyperglycemia develops. ${ }^{6}$ We predicted the reduction of skeletal muscle to be associated with increased insulin resistance and risk of type 2 diabetes mellitus. A 4.6-year follow-up of 147 healthy Mexican men and women over 60 years of age indicated that hyperinsulinemia, as an early marker of insulin resistance, was significantly associated with reduced mass of appendicular skeletal muscle after adjusting for age, baseline total body fat, height and physical activity. ${ }^{18}$ A 12-year cohort study of 6895 Korean men and women aged 40-69 years 
Table 3 Multivariable†HR for dysglycemia and diabetes according to serum creatinine categories among subjects with normal glucose levels at baseline

\begin{tabular}{|c|c|c|c|c|c|c|c|c|c|c|c|}
\hline & & & \multicolumn{9}{|c|}{ Serum creatinine $(\mathrm{mg} / \mathrm{dL})$} \\
\hline & & & $0.38-0.69$ & \multicolumn{2}{|l|}{$0.70-0.79$} & $0.80-0.89$ & $0.90-1.10$ & \multicolumn{3}{|c|}{ Total } & $\begin{array}{l}\text { P for } \\
\text { trend }\end{array}$ \\
\hline $\begin{array}{l}\text { No. of subjects with } \\
\text { dysglycemia }\end{array}$ & & & 78 & \multicolumn{2}{|l|}{187} & 188 & 143 & \multicolumn{3}{|c|}{596} & \\
\hline $\begin{array}{l}\text { Age-adjusted HR } \\
(95 \% \mathrm{Cl})\end{array}$ & & & $1.5(1.1 \text { to } 1.9)^{\star \star}$ & \multicolumn{2}{|l|}{1.1 (0.9 to 1.3$)$} & $1.0(0.8$ to 1.2$)$ & \multicolumn{4}{|l|}{1.00} & 0.02 \\
\hline Age $<43$ years & \multicolumn{2}{|c|}{ Cases/subjects } & $38 / 180$ & \multicolumn{2}{|l|}{$78 / 514$} & $84 / 587$ & $53 / 356$ & \multicolumn{3}{|c|}{$253 / 1637$} & \\
\hline $\begin{array}{l}\text { Multivariable HR } \\
(95 \% \mathrm{Cl})\end{array}$ & & & $1.8(1.2 \text { to } 2.8)^{\star \star}$ & \multicolumn{2}{|l|}{1.3 (0.9 to 1.8$)$} & $1.2(0.8$ to 1.7$)$ & 1.00 & & & & $<0.01$ \\
\hline Age $\geq 43$ years & Cases/sub & ects & $40 / 133$ & $109 / 438$ & & $104 / 477$ & $90 / 361$ & & $343 / 1$ & 409 & \\
\hline $\begin{array}{l}\text { Multivariable HR } \\
(95 \% \mathrm{Cl})\end{array}$ & & & $1.5(1.0 \text { to } 2.2)^{\star}$ & $1.0(0.7$ to 1.3 & & 1.0 (0.8 to 1.4$)$ & 1.00 & & & & 0.09 \\
\hline $\mathrm{BMI} \geq 25 \mathrm{~kg} / \mathrm{m}^{2}$ & Cases/sub & ects & $29 / 89$ & $81 / 259$ & & $70 / 326$ & $65 / 264$ & & $245 / 9$ & & \\
\hline $\begin{array}{l}\text { Multivariable HR } \\
(95 \% \mathrm{Cl})\end{array}$ & & & 1.5 (0.9 to 2.3$)$ & 1.4 (1.0 to 2.0 & & $1.0(0.7$ to 1.4$)$ & 1.00 & & & & 0.04 \\
\hline $\begin{array}{l}\text { With family history of } \\
\text { diabetes }\end{array}$ & Cases/sub & ects & $56 / 244$ & $156 / 824$ & & $156 / 925$ & $114 / 611$ & & $482 / 2$ & 604 & \\
\hline $\begin{array}{l}\text { Multivariable } \neq \mathrm{HR} \\
(95 \% \mathrm{Cl})\end{array}$ & & & 0.9 (0.5 to 1.6$)$ & $0.9(0.5$ to 1.4 & & $0.8(0.5$ to 1.3$)$ & 1.00 & & & & 0.61 \\
\hline $\begin{array}{l}\text { Without family } \\
\text { history of diabetes }\end{array}$ & Cases/sub & ects & $22 / 69$ & $31 / 128$ & & $32 / 139$ & $29 / 106$ & & $114 / 4$ & & \\
\hline $\begin{array}{l}\text { Without high } \\
\text { physical activity }\end{array}$ & Cases/sub & ects & $21 / 110$ & $98 / 334$ & & $73 / 414$ & $56 / 325$ & & $228 / 1$ & , 183 & \\
\hline Multivariable§ HR & & & $1.6(1.1-2.2)^{\star}$ & 0.9 (0.7 to 1.2 & & 0.9 (0.7 to 1.2$)$ & 1.00 & & & & $<0.01$ \\
\hline & & 0.38 & $8-0.69$ & $0.70-0.79$ & & -0.89 & $90-1.10$ & Total & & $P$ for & trend \\
\hline Total subjects & & 313 & & 952 & 10 & 7 & & 3046 & & & \\
\hline $\begin{array}{l}\text { No. of subjects with } \\
\text { dysglycemia }\end{array}$ & & 78 & & 187 & 18 & 12 & & 596 & & & \\
\hline Multivariable HR $(95$ & $\% \mathrm{Cl})$ & 1.5 & $(1.1 \text { to } 1.9)^{\star \star}$ & 1.1 (0.9 to 1.4$)$ & & $(0.8$ to 1.3$)$ & 00 & & & 0.01 & \\
\hline No. of subjects with & diabetes & 20 & & 33 & 33 & 2 & & 115 & & & \\
\hline Multivariable HR (95 & $\% \mathrm{Cl})$ & 1.9 & $(1.0 \text { to } 3.4)^{\star \star}$ & $1.0(0.6$ to 1.7$)$ & & $(0.6$ to 1.6$)$ & 00 & & & 0.1 & \\
\hline
\end{tabular}

Test for significance: ${ }^{*} \mathrm{P}<0.05,{ }^{* \star} \mathrm{P}<0.01$.

†Adjusted for age, BMI, family history, smoking status, alcohol intake category and leisure time physical activity.

$\ddagger$ Adjusted for age, BMI, smoking status, alcohol intake category and leisure time physical activity.

$\S$ Adjusted for age, BMI, family history, smoking status and alcohol intake category.

BMI, body mass index.

also showed a significant inverse association between muscle mass index, defined as the weight-adjusted appendicular skeletal muscle mass, and the risk of type 2 diabetes mellitus. ${ }^{19}$
The reduction of skeletal muscle may be associated with an increased risk of diabetes because of a reduction in both insulin resistance and insulin secretion. A cross-sectional study of Japanese men and women aged 
40-79 years without diabetes showed a significant positive correlation between appendicular muscle mass index and clinical parameters of both $\beta$-cell function and insulin resistance. ${ }^{20}$

A cross-sectional analysis of 13644 subjects in the National Health and Nutrition Examination Survey III showed that a $10 \%$ increase in skeletal muscle index, the ratio of total skeletal muscle mass (estimated by bioelectrical impedance) to total body weight, was associated with an $11 \%(95 \%$ CI $6 \%$ to $15 \%)$ relative reduction in HOMA-IR and a $12 \%$ (95\% CI $1 \%$ to $21 \%$ ) relative reduction in the prevalence of prediabetes or overt diabetes after adjusting for age, ethnicity, sex and generalized and central obesity. ${ }^{21}$ In that study, increased muscle mass (relative to body size) was associated with greater insulin sensitivity and a lower risk of prediabetes or overt diabetes. $^{21}$

Insulin sensitivity is reported to be higher in people with low visceral fat mass, but insulin secretion was much lower in East Asians (including Japanese) than in Africans and Caucasians, because of their lower visceral fat mass and smaller body size. ${ }^{22}$ Further reduction of skeletal muscle (as indicated by lower serum creatinine levels) in East Asians is likely to increase the risk of type 2 diabetes mellitus and dysglycemia.

In addition to low skeletal muscle mass, the increased risk of diabetes or dysglycemia associated with low serum creatinine levels may be explained in part by glomerular hyperfiltration. Glomerular hyperfiltration was observed in $6 \%-73 \%$ of patients with type 2 diabetes mellitus and the peak filtration rate may be seen in prediabetes or shortly after the onset of diabetes. ${ }^{23}$ Moreover, a cross-sectional study of 2584 men and women aged $12-17$ years showed that persons with glomerular hyperfiltration (estimated glomerular filtration rate (eGFR) $\geq 120 \mathrm{~mL} /$ $\min 1.73 \mathrm{~m}^{2}$ ) had higher mean levels of fasting insulin after adjusting for BMI. ${ }^{24}$ In that study, eGFR was defined by the Schwartz equation, that is, eGFR $(\mathrm{mL} / \mathrm{min} 1.73$ $\left.\mathrm{m}^{2}\right)=0.413 \times$ height $(\mathrm{cm}) /$ serum creatinine $(\mathrm{mg} / \mathrm{dL})$, so another possibility is that glomerular hyperfiltration led to low serum creatinine levels.

Both diabetes and dysglycemia have been associated with risk of cardiovascular disease. ${ }^{1-3}$ Therefore, the prevention and control of diabetes and dysglycemia through lifestyle modifications such as increased physical activity or resistance exercise are important to increase skeletal muscle mass. Nutritional control may also be important, especially by increasing intake of amino acids or protein. A randomized crossover study of 41 elderly normal weight men and women aged 66-84 years with sarcopenia demonstrated that nutritional supplementation with an amino acids mixture significantly increased whole-body lean mass compared with controls. ${ }^{25}$

The strengths of the present study include the following: prospective cohort study of middle-aged Japanese men, standardized measurement of creatinine and glucose in a single laboratory, annual follow-up examinations with high follow-up rates and adjustment for potential confounding factors such as family history of diabetes, physical activity and smoking status, which were not taken into account in a recent Japanese cohort study. ${ }^{12}$

Our study also has several limitations. First, our study population was a single ethnic group of middle-aged male workers in an urban city, so it is unclear whether our results can be applied to female, younger or older people, other Asian people or Caucasians. Second, we did not measure fasting serum insulin at baseline, so the relationship with insulin resistance and insulin secretion was not examined.

In conclusion, low serum creatinine levels were associated with an increased risk of type 2 diabetes mellitus and dysglycemia.

Acknowledgements The authors wish to thank the research staff of the 0saka Center for Cancer and Cardiovascular Disease Prevention, and health professionals in the survey communities for their valuable assistance. The authors also thank Alice Tait, PhD, from Edanz Group (www.edanzediting.com/ac) for editing a draft of this manuscript.

Contributors MT was the lead author, conceived the original idea for the study, collected the data, performed the data analyses and wrote the manuscript. HI revised the manuscript, contributed to the interpretation of the data and added critical comments. IM, YS, MH-T, AK, TO and MK were involved in data collection and revised the manuscript and contributed with comments. HI was responsible for the overall supervision and contributed to the data analysis and the manuscript. All authors had access to the data, commented on the manuscript drafts and approved the final version.

Funding This research received no specific grant from any funding agency in the public, commercial or not-for-profit sectors.

Competing interests None declared.

Patient consent Obtained.

Ethics approval Osaka Center for Cancer and Cardiovascular Disease. Provenance and peer review Not commissioned; externally peer reviewed. Data sharing statement The datasets generated during and/or analyzed during the current study are not publicly available due to restrictions based on privacy regulations and informed consent of the participants, but are available from the corresponding author on reasonable request.

Open Access This is an Open Access article distributed in accordance with the Creative Commons Attribution Non Commercial (CC BY-NC 4.0) license, which permits others to distribute, remix, adapt, build upon this work non-commercially, and license their derivative works on different terms, provided the original work is properly cited and the use is non-commercial. See: http://creativecommons.org/ licenses/by-nc/4.0/

(c) Article author(s) (or their employer(s) unless otherwise stated in the text of the article) 2018. All rights reserved. No commercial use is permitted unless otherwise expressly granted.

\section{REFERENCES}

1. Newman JD, Schwartzbard AZ, Weintraub HS, et al. Primary prevention of cardiovascular disease in diabetes mellitus. J Am Coll Cardiol 2017;70:883-93.

2. Stefan N, Fritsche A, Schick F, et al. Phenotypes of prediabetes and stratification of cardiometabolic risk. Lancet Diabetes Endocrinol 2016;4:789-98.

3. Huang Y, Cai X, Mai W, et al. Association between prediabetes and risk of cardiovascular disease and all cause mortality: systematic review and meta-analysis. BMJ 2016;355:i5953.

4. Standl E, Schnell O, Ceriello A. Postprandial hyperglycemia and glycemic variability: should we care? Diabetes Care 2011;34 Suppl 2:S120-S127.

5. Katz LD, Glickman MG, Rapoport S, et al. Splanchnic and peripheral disposal of oral glucose in man. Diabetes 1983;32:675-9. 
6. DeFronzo RA, Tripathy D. Skeletal muscle insulin resistance is the primary defect in type 2 diabetes. Diabetes Care 2009;32 Suppl 2:S157-S163.

7. Rattarasarn C, Leelawattana R, Soonthornpun S. Contribution of skeletal muscle mass on sex differences in 2-hour plasma glucose levels after oral glucose load in Thai subjects with normal glucose tolerance. Metabolism 2010;59:172-6.

8. Baxmann AC, Ahmed MS, Marques NC, et al. Influence of muscle mass and physical activity on serum and urinary creatinine and serum cystatin C. Clin J Am Soc Nephrol 2008;3:348-54.

9. Nayak BS, Butcher DM, Bujhawan S, et al. Association of low serum creatinine, abnormal lipid profile, gender, age and ethnicity with type 2 diabetes mellitus in Trinidad and Tobago. Diabetes Res Clin Pract 2011;91:342-7.

10. Hielmesæth J, Røislien J, Nordstrand N, et al. Low serum creatinine is associated with type 2 diabetes in morbidly obese women and men: a cross-sectional study. BMC Endocr Disord 2010;10:6.

11. Harita N, Yoneda $\mathrm{T}$, Hayashi $\mathrm{T}$, et al. Lower serum creatinine is a new risk factor of type diabetes. Diabetes Care 2009;32:424-6.

12. Kashima $\mathrm{S}$, Inoue $\mathrm{K}$, Matsumoto $\mathrm{M}$, et al. Low serum creatinine is a type 2 diabetes risk factor in men and women: The Yuport Health Checkup Center cohort study. Diabetes Metab 2017;43:460-4.

13. World Health Organization. Definition and diagnosis of diabetes mellitus and intermediate hyperglycemia: report of a WHO/IDF consultation. Geneva: World Health Organization, 2006.

14. Moon JS, Lee JE, Yoon JS. Variation in serum creatinine level is correlated to risk of type 2 diabetes. Endocrinol Metab 2013;28:207-13.

15. Patel SS, Molnar MZ, Tayek JA, et al. Serum creatinine as a marker of muscle mass in chronic kidney disease: results of a crosssectional study and review of literature. J Cachexia Sarcopenia Muscle 2013;4:19-29.
16. Keshaviah PR, Nolph KD, Moore HL, et al. Lean body mass estimation by creatinine kinetics. J Am Soc Nephrol 1994;4:1475-85.

17. Thiebaud D, Jacot E, DeFronzo RA, et al. The effect of graded doses of insulin on total glucose uptake, glucose oxidation, and glucose storage in man. Diabetes 1982;31:957-63.

18. López Teros MT, Ramírez C FA, Alemán-Mateo H. Hyperinsulinemia is associated with the loss of appendicular skeletal muscle mass at 4.6 year follow-up in older men and women. Clin Nutr 2015;34:931-6.

19. Son JW, Lee SS, Kim SR, et al. Low muscle mass and risk of type 2 diabetes in middle-aged and older adults: findings from the KoGES. Diabetologia 2017;60:865-72.

20. Sakai $S$, Tanimoto $K$, Imbe A, et al. Decreased $\beta$-cell function is associated with reduced skeletal Muscle mass in Japanese subjects without diabetes. PLoS One 2016;11:e0162603.

21. Srikanthan P, Karlamangla AS. Relative muscle mass is inversely associated with insulin resistance and prediabetes. Findings from the third National Health and Nutrition Examination Survey. J Clin Endocrinol Metab 2011;96:2898-903.

22. Kodama K, Toda K, Tojjar D, et al. Ethnic differences in the relationship between insulin sensitivity and insulin response. Diabetes Care 2013;36:1789-96.

23. Tonneijck L, Muskiet MH, Smits MM, et al. Glomerular hyperfiltration in diabetes: Mechanisms, clinical significance, and treatment. J Am Soc Nephrol 2017;28:1023-39.

24. Lee AM, Charlton JR, Carmody JB, et al. Metabolic risk factors in nondiabetic adolescents with glomerular hyperfiltration. Nephrol Dial Transplant 2017;32:gfw231-24.

25. Solerte SB, Gazzaruso C, Bonacasa R, et al. Nutritional supplements with oral amino acid mixtures increases whole-body lean mass and insulin sensitivity in elderly subjects with sarcopenia. Am J Cardiol 2008;101:S69-77. 